\title{
PERFIL DO ENFERMEIRO DE UNIDADES AMBULATORIAIS DO INAMPS NO BRASIL*
}

Taka Oguisso **

OGUISSO, T. Perfil do enfermeiro de unidades ambulatoriais do INAMPS no Brasil. Rev. Esc. Enf. USP, São Paulo, 24(1):77-92, abr. 1990.

O estudo teve como objetivo traçar o perfil de enfermeiro atuante nas unidades ambulatoriais do INAMPS tendo em vista oferecer subsidios aos órgãos formadores $e$ utilizadores de enfermeiros, ds entidades de classe e aos próprios profissionais para melhor conhecimento do assunto. Para isso foram levantados alguns conjuntos de variáveis sobre: a) caracteristicas pessoais e profissionais, bem como satisfação no trabalho e percepção de apoio da chefia; b) as atividades executadas com mais frequência pelos enfermeiros.

Identificados esses conjuntos de variáveis, eles foram cotejados dentro do próprio conjunto e de um conjunto com o outro, para verificaçäo da existência de possiveis relações.

Do total de 28.953 enfermeiros cadastrados no COFEN em 1984, apenas 3.414 (11,8\%) estavam trabalhando em todo o INAMPS. Destes, 1.158 estavam lotados nas unidades ambulatoriais, aos quais foram enviados questiomários no periodo de março a dezembro de 1984.

Os dados de 927 questionários recebidos $(80,1 \%)$ revelaram que havia predominancia do sexo feminino (94,3\%), maioria de casados, faixa etária de 30-49 anos de idade, diplomação em enfermagem e admissão na Previdência Social na década de 70 , satisfação no trabalho $(83,6 \%)$ percep̧̧ão de apoio dachefia $(75,2 \%)$, nivel de preparo em cursos de habilitação e de especialização $(71,3 \%)$ e em programas de educação continuada $(84,1 \%)$.

As atividades desenvolvidas pelo enfermeiro era: supervisão do pessoal de enfermagem $(39,3 \%)$, assistência direta ao cliente/paciente $(36,7 \%)$, educação ou orientação para a saúde do paciente/familia $(21,7 \%)$, funçōes administrativas $(17,9 \%)$ e treinamento de pessoal $(3,6 \%)$.

Estabelecidas as relações entre as diversas variáveis, observou-se que não havia relação entre o prepara em cursos formais ou em programas de educação continuada com satisfação no trabalho ou com percep̧ão de apoio da chefia. Constatou-se tambrém que os profissionais que atuam em treinamento de pessoal $e$ em atividades educativas relacionadas com clientes/pacientes eram as mais satisfeitos, e os que executavam supervisão de pessoal e atividades administrativas os que mais sentiam apoio da chefia para implantafãa de nova rotina de enfermagem.

UNITERMOS: Serviços de enfermagem. Assistência ambulatorial. Previdência social - Brasil.

* Tese de livie-docencia apresentada à Escola de Enfermagem da Universidade de Săo Paulo, em 2987. Considerando que a rede de unidades ambulatoriais rlo INAMPS existento em cada Estado da Federaçăo passou a compor os Serviços Uniflcados de Saúde (SUDS), fato esse previsto na tese de uma certa maneira, fol felta uma atualizacbo de terminologia, mantendo-se, porém, a denominaçăo daquela entidade tal como a tege fol defendida. (Apresentação condenstada).

* Enfermeira. Consultora do Conselho Internacional de Enfermeiras, Genebra, Suiça.

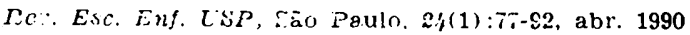




\section{INTRODUÇÃO}

Traçar o perfil do enfermeiro tem se convertido em uma das preocupaçōes de entidades de classe de enfermagem para definir quem é o enfermeiro e qual o papel profissional que tem desempenhado no Brasil. O perfil profissional assim descrito pode se constituir em um instrumento fundamental, tanto para a administração de serviços como para a área de ensino, seja na elaboração de currículos e programas, seja na "seleção de experiências e estabelecimento de critérios de avaliação da aprendizagem" 16 .

Segundo AQUINO2 "cada organização tem sua história, seus valores, seus pontos fortes e fracos, suas carocterísticas específicas formadoras de sua cultura, a cue o profissional deve atender e adaptar-se a ela da melhor maneira possivel".

O "Instituto Nacional de Assistência Médica da Previdência Social" (INAMPS) pode ser citado como um exemplo desse tipo de organização, com sua história, seus valores, sua cultura e peculiaridades, e também como uma das maiores instituições utilizadoras de recursos humanos do setor saúde, inclusive de enfermeiros.

Na verdade, desde a implantação da Previdência Social no Brasil, em 1919, essa grande instituição federal passou por sucessivas reformas, unificaçōes e reorganizaçōes de seus serviços visando a racionalização dos sistemas de trabalho e a universalização da assistência. Finalmente culminou com a sua recente integração aos serviços estaduais de saúde, por meio de convênios para implantação do Sistema Unificado e Descentralizado de Saúde (SUDS), juntamente com a Secretaria de Saúde em cada Estado do país. Era imperativo tido como necessário para eliminar a pluralidade de instituições de assistência à saúde.

Especialmente a partir da realização da Conferência Internacional sobre Cuidados Primários de Saúde ${ }^{13}$, em Alma-Ata, 1978, tornou-se mais intenso o movimento para unificação do sistema de prestação da assistência à saúde. Com vistas a estender a cobertura, tal sistema incluia a utilização da estratégia de serviços básicos ou assistência primária de saúde e a participação predominante de pessoal auxiliar.

Considerando que a minoria desse pessoal auxiliar é representada tradicionalmente pela área de enfermagem, o enfermeiro seria o elemento natural e mais apropriado para treinamento e supervisão do mesmo. Além do seu papel fundamental na equipe multi-disciplinar de saúde, o enfermeiro, dada sua formação acadêmica curricular, tem conhecimentos e habilidades para atender às necessidades de saúde das pessoas, grupos e comunidades nos vários niveis de assistência.

Na grande rede de serviços próprios instalados da Previdência Social, que foram integrados à rede da Secretaria de Saúde formando os Serviços Unificados de Saúde (SUDS), já existia um considerável contingente de enfermeiros.

Dada a importância do papel do enfermeiro na realidade prática dos serviços ambulatoriais, surgiu o interesse pelo estudo do perfil desse 
profissional em exercicio nas unidades ambulatoriais pertencentes ao INAMPS como contribuição:

- à Previdência Social, ou à sua sucedânea, para melhor compreender quem é esse profissional que está atuando na rede de serviços ambulatoriais, quais suas características pessoais, seu preparo, alguns de seus anseios e opiniōes e as atividades que executa;

- às escolas e cursos de graduação em enfermagem, para que possam reforçar em seus programas os conhecimentos, assim como as experiências e a formação de atitudes, necessários ao pleno exercício profissional de seus egressos que poderão atuar em unidades ambulatoriais;

- às entidades de classe para justificar proposições ou assessorar órgãos governamentais e autoridades em seus planos, projetos e programas de saúde;

- aos enfermeiros, enfim, para que tenham uma visão geral do que é realizado em outras unidades ambulatoriais c, assim, possam individualmente fazer auto-avaliação de seu desempenho ou reavaliar sua potencialidade e colocá-la a serviço da instituição na qual trabalha.

São, pois, objetivos deste estudo:

1. Identificar caracteristicas pessoais e profissionais do enfermeiro que trabalha nas unidades ambulatoriais da Previdência Social.

2. Identificar as atividades mais executadas nas unidades ambulatoriais da Previdência Social, especialmente as que são executadas por enfermeiros.

3. Verificar a existência de relaçōes entre aquelas características pessoais e profissionais e as atividades executadas por enfermeiros.

\section{MATERIAL E MÉTODO}

Este estudo é continuação de um trabalho anterior intitulado "Assistência Primária de Saúde no INAMPS, em São Paulo e Rio de Janeiro - contribuição do enfermeiro" 12. A escolha do tema foi baseada na publicação, em 1982, do documento "Perfil do Enfermeiro" pela Associação Brasileira de Enfermagem e Conselho Federal de Enfermagem 8, reforçado posteriormente por um perfil legal com a promulgaçấo da legislação profissional da enfermagem em $1986^{6}$ e em $1987^{5}$.

Embora o universo dos dois estudos seja constituído de enfermeiros de unidades ambulatoriais da Previdência Social, o enfoque e a abrangência de ambos são diferentes: o primeiro estudo focalizou as atividades de Assistência Primária de Saúde dos enfermeiros nos Estados de São Paulo e Rio de Janeiro, e este detém-se nas características pessoais e profissionais do INAMPS em todo o pais.

Os dados para este estudo foram colhidos somente nas unidades ambulatoriais pertencentes à rede de serviços próprios da Previdência Social, incluindo-se, porém, toda a população de enfermeiros lotada nesses serviços. Essa população, por trabalhar na mesma instituição da esfera do governo federal, encontrava-se regida por iguais normas e 
regulamentos, sujeita a condições de trabalho mais ou menos homogêneas e padrão de remuneração equivalente.

Segundo dados do Conselho Federal de Enfermagem (COFEN) ${ }^{14}$, o número total de enfermeiros inscritos em 1984, época da coleta de dados, era de 28.953. Na mesma época, o número de enfermeiros lotados no INAMPS, em todos os serviços, sejam hospitalares, ambulatoriais, administrativos ou outros, era de 3.414, conforme pode ser observado na Tabela 1. Por último, as unidades da Federação (UF) foram identificadas por abreviaturas conforme estabelecido pelas "Normas de Apresentação Tabular" da Fundação Instituto Brasileiro de Geografia e Estatística ${ }^{10}$.

T A B E L A 1

NOMERO E I'ORCENTAGEM DE ENFHRMEIROS INSCRITOS NO COFEN E ATIVOS NO INAMPS POR UNIDADE DA FEDERAÇAO. BRASIL, 1984.

\begin{tabular}{|c|c|c|c|c|c|}
\hline \multirow{3}{*}{$\mathbf{U F}$} & \multicolumn{4}{|c|}{ Instituigōes } & \multirow{3}{*}{$\begin{array}{l}\% \text { de enfos. no } \\
\text { INAMPS sobre } \\
\text { inscritos no } \\
\text { COFEN. }\end{array}$} \\
\hline & \multicolumn{2}{|c|}{ CUFEN (1) } & \multicolumn{2}{|c|}{ INAMPS (2) } & \\
\hline & n. & $\%$ & n.甲 & $\%$ & \\
\hline $\mathbf{A M}$ & 435 & 1,5 & 32 & 0,9 & 7,4 \\
\hline $\mathbf{P A}$ & 670 & 2,3 & 42 & 1,2 & 6,3 \\
\hline MA & 429 & 1,4 & 86 & 2,5 & 20,0 \\
\hline $\mathbf{P I}$ & 167 & 0,6 & 16 & 0,5 & 9,6 \\
\hline $\mathrm{CE}$ & 1272 & 4,4 & 147 & 4,3 & 11,6 \\
\hline $\mathbf{R N}$ & 349 & 1,2 & 29 & 0,8 & $\mathbf{8 , 3}$ \\
\hline PB & 950 & 3,3 & 95 & 2,8 & 10,0 \\
\hline PE & 1032 & 3,6 & 232 & 6,9 & 22,5 \\
\hline AL & 186 & 0,6 & 20 & 0,6 & 10,8 \\
\hline $\mathbf{S E}$ & 194 & 0,7 & 14 & 0,4 & 7,2 \\
\hline BA & 1692 & 5,5 & 161 & 4,7 & 10,1 \\
\hline $\mathbf{M G}$ & 2274 & 7,7 & 191 & 3,6 & 8,4 \\
\hline ES & - & - & 17 & 0,5 & 0,3 \\
\hline RJ & 3819 & 20,1 & 1590 & 46,6 & 27,3 \\
\hline SP & 7992 & 27,6 & 328 & 9,6 & 4,1 \\
\hline PR & 920 & 3,2 & 36 & 1.1 & 3,9 \\
\hline SC & 639 & 2,2 & 48 & 1,4 & 7,6 \\
\hline RS & 2265 & 7,8 & 117 & 3,4 & $\mathbf{5 , 2}$ \\
\hline MS & - & 一 & 3 & 0,1 & 1,3 \\
\hline $\mathbf{M T}$ & 230 & 0,8 & 6 & 0,1 & 2,2 \\
\hline GO & 700 & 2,4 & 80 & 2,3 & 11,4 \\
\hline DF & 830 & 2,9 & 125 & 3,7 & 14,9 \\
\hline Total & 28953 & 100,0 & 3414 & 100,0 & 11,8 \\
\hline
\end{tabular}

Fontes: (1) COFEMN-NN, Rlo de Janelro, $7(1$ e 2):3, Jan/Jun 1984.

(2) Coordenadoria de Enfermagem, Secretaria de Medicina Social. INAMPS. Rio de Janeiro, março de 1984. 
A Tabela I apresenta omissão de dados no Espírito Santo e Mato Grosso do Sul, porque nessas Unidades da Federação não estavam instalados os respectivos Conselhos Regionais de Enfermagem; os enfermeiros residentes nessas duas Unidades estavam inscritos nos Conselhos Regionais de Enfermagem do Rio de Janeiro e Mato Grosso, respectivamente. Portanto, no número de enfermeiros indicados para o Rio de Janeiro estão incluidos enfermeiros do Espírito Santo; no de Mato Grosso, os de Mato Grosso do Sul. Não foi possível obter esses dados desmembrados junto ao Conselho Federal de Enfermagem (COFEN). O Conselho Regional do Espírito Santo foi reativado, em data posterior ao estudo em pauta. E Mato Grosso do Sul ainda não conta com Conselho Regional de Enfermagem.

Pela Tabela 1 observa-se que quase a metade da população de enfermeiros $(47,7 \%)$ está localizada no eixo São Paulo-Rio de Janeiro; esse fenômeno verifica-se também em outras profissões e já foi constatado no referido trabalho anterior.

Merecem destaque as Unidades Federadas do Rio de Janeiro, Pernambuco e Maranhão onde, dos respectivos totais de enfermeiros cadastrados no COFEN, mais de $20 \%$ estão empregados no INAMPS. O Estado de São Paulo, apesar de contar com a maior população de enfermeiros cadastrados no COFEN $(27,6 \%)$ tem apenas $4,1 \%$ trabalhando no INAMPS.

No Rio de Janeiro (oride se incluem os enfermeiros do ES), além de ter empregado no INAMPS $27,3 \%$ da população cadastrada, esses enfermeiros representam também quase a metade de toda a populaçâo $(46,6 \%)$ de enfermeiros ativos no INAMPS.

\subsection{População}

Embora uma equipe de enfermagem inclua diversas categorias profissionais a opção para estudar o perfil de uma única categoria decorreu de três motivos:

- necessidade de delimitar o problema;

- facilidade para realizar a investigação;;

- maior dominio e conhecimento da profissão do enfermeiro por parte da autora.

Dessa forma, a população abrangida nesta investigação representou a totalidade do universo de enfermeiros do INAMPS, lotada apenas nas unidades ambulatoriais, localizada em todo o território brasileiro. Esso população foi constituíảa por 1.158 enfermeiros, dos quais $927(80,1 \%)$ responderam o questionário que lhes foi enviado, como consta na Tabela 2.

Conforme mostra a Tabcla 2, todas as Unidades da Federação foram incluídas no estudo, com exceção do Acre Rondonia, porque, na ocasião da coleta de dados não existiam enfermeiros nos quadros do INAMPS desses Estados. 
T A B E L A 2

NUMERO E PORCENTAGEM DE EINFERMEIROS LOTADOS EM UNIDADES AMBULATORIALS DO INAMPS E QUE RESPONDERAM AO QUESTIONARIO POR UNIDADES DA FHEERAÇAO. BRASIL, 1984.

\begin{tabular}{|c|c|c|c|c|c|}
\hline \multirow{2}{*}{$\mathbf{U F}$} & \multicolumn{2}{|c|}{$\begin{array}{c}\text { Unidades } \\
\text { Ambbulatoriais * }\end{array}$} & \multicolumn{2}{|c|}{ Respondentes } & \multirow{2}{*}{$\begin{array}{l}\% \text { de respondentes } \\
\text { sobre enfermeiros } \\
\text { do unid. ambulat. }\end{array}$} \\
\hline & N.9 & $\%$ & N.P & $\%$ & \\
\hline $\mathbf{A M}$ & 30 & 2,6 & 22 & 2,5 & 73,3 \\
\hline PA & 37 & 3,2 & 30 & 3,2 & 81,1 \\
\hline MA & 16 & 1,4 & 14 & 1,5 & 87,5 \\
\hline PI & 14 & 1,2 & 12 & 1,3 & 85,7 \\
\hline $\mathrm{CE}$ & 41 & 3,5 & 34 & 3,7 & 82,9 \\
\hline RN & 25 & 2,1 & 20 & 2,2 & 80,0 \\
\hline PB & 68 & 5,9 & 53 & 5,7 & 77,9 \\
\hline $\mathbf{P E}$ & 47 & 4,1 & 43 & 4,6 & 91,5 \\
\hline AL & 17 & 1,5 & 14 & 1,5 & 82,4 \\
\hline $\mathbf{S E}$ & 13 & 1,1 & 11 & 1,2 & 84,6 \\
\hline BA. & 57 & 4,9 & 57 & 6,1 & 100,0 \\
\hline MG & 168 & 14,5 & 141 & 15,2 & 83,9 \\
\hline ES & 17 & 1,5 & 17 & 1,8 & 100,0 \\
\hline $\mathbf{R J}$ & 311 & 26,9 & 213 & 23,0 & 68,5 \\
\hline SP & 112 & 9,7 & 103 & 11,1 & 92,0 \\
\hline PR & 30 & 2,6 & 24 & 2,6 & 80,0 \\
\hline sc & 29 & 2,6 & 29 & 3,1 & 100,0 \\
\hline RS & 69 & 6,0 & 40 & 4,4 & 58,0 \\
\hline MS & 3 & 0,2 & 3 & 0,3 & 100,0 \\
\hline $\mathbf{M T}$ & 4 & 0,3 & 4 & 0,4 & 100,0 \\
\hline GO & 28 & 2,4 & 24 & 2,6 & 85,7 \\
\hline DE & 22 & 1,9 & 19 & 2,0 & 86,4 \\
\hline Total & 1158 & 100,0 & 927 & 100,0 & 80,1 \\
\hline
\end{tabular}

* Coordenadoria de Enfermagem da Secretaria de Medicina Social co INAMPS, Rio de Janeiro , 1984.

A população de 927 enfermeiros estava distribuída em 286 serviços ambulatoriais $(51,9 \%)$, do total de 551 existentes em 21 Unidades da Federação e no Distrito Federal; concluiu-se que 265 serviços $(48,1 \%)$ não contavam com enfermeiros em seus quadros, funcionando apenas com auxiliares de enfermagem e auxiliares operacionais de serviços diversos (atendentes); e muitos, somente com essa última categoria, além dos médicos.

Para a análise de dados referentes aos Estados de São Paulo e Rio de Janeiro foram aproveitadas as respostas de questionários distribuídos em 1982, por ocasião do primeiro estudo sobre Assistência Primária de Saúde, já mencionado. 
Embora o INAMPS nesses dois Estados tenha recebido novos contingentes de enfermeiros concursados após o ano de 1982, o questionário para a pesquisa de 1984 não foi redistribuido por três motivos: tratavase do mesmo instrumento da pesquisa anterior; iria dificultar a separação dos profissionais que já haviam respondido anteriormente dos que ainda não o haviam feito e, o que é mais importante, o aumento do contingente não teve muita significância. Na verdade, em ambas as Unidades da Federação o crescimento foi de menos de $9 \%$, sendo $3,7 \%$ em São Paulo e 8,7\% no Rio de Janeiro.

Com esse reduzido crescimento em dois anos, o número de respostas de São Paulo, onde fora obtido $100 \%$ de retorno do questionário no estudo anterior, passou a ser de $92,0 \%$, quando o total de questionários devolvidos foi aplicado ao número de enfermeiros existentes em unidades ambulatoriais, em 1984. Já no Rio de Janeiro, o percentual de devoluções : do questionário, que era de $78,0 \%$ no estudo anterior, passou para $68,5 \%$ na presente investigação.

Foram excluidos deste estudo:

- os enfermeiros lotados nos hospitais próprios do INAMPS e aí exercendo atividades hospitalares;

- os enfermeiros que se encontravam em atividades administrativas na sede das Superintendências Regionais;

- os que executavam funções em nivel de Direção Geral nos Departamentos e Secretarias, junto à Previdência do INAMPS no Rio de Janeiro.

Março de 1984 foi a data-base adotada para coleta de informações quantitativas de pessoal em todo o Brasil, exceto em São Paulo e Rio de Janeiro para os quais valeu a data-base de março de 1982, ocasião da coleta dessas mesmas informaçōes.

Somadas as informações colhidas em todo o Brasil, inclusive as de São Paulo e Rio de Janeiro feitas pelo estudo anterior, foi encontrado um total de 1.158 enfermeiros lotados nos serviços ambulatoriais do INAMPS, conforme mostra a Tabela ${ }^{2}$. Excluídos 18 enfermeiros de São Paulo e Rio de Janeiro por terem respondido ao pré-teste realizado antes mesmo da primeira investigação, restaram, na população-alvo, 1.140 profissionais atingidos pelo presente estudo.

Do total de 1.140 questionários enviados, foram recebidas 927 respostas, ou seja, $81,3 \%$.

\subsection{Variáveis}

Neste estudo foram selecionados e estabelecidos dois conjuntos de variáveis: caracterização da população e atividades executadas nas unidades ambulatoriais, que foram depois cotejadas entre si a fim de verificar a existência de possiveis relaçōes de um conjunto com o outro, assim como as relações dos diversos desdobramentos do mesmo conjunto de variáveis. 


\subsection{Instrumento}

O instrumento para a coleta de dados foi constituido por um questionário de 30 perguntas distribuidas em sete folhas, além da página de rosto.

Embora tenha sido utilizado o mesmo instrumento do trabalho anterior, para esta investigação foram aproveitadas apenas as respostas de questōes pertinentes ao objeto do estudo, isto é, ao perfil do enfermeiro. Tais respostas foram devidamente codificadas para que a apuração fosse feita por processo eletrônico. A folha inicial do questionário apresentava vários considerandos cujo objetivo era sensibilizar a população-alvo a responder ao mesmo; continha igualmente, instruções de preenchimento, prazo e endereço para devolução.

Não foi realizado pré-teste para a presente investigação, uma vez que este já havia sido feito por ocasião do estudo anterior.

\section{APRESENTAÇÃO E DIISCUSSÃO DOS RESULTADOS}

\subsection{Caracterização da população}

O universo de 927 enfermeiros incluidos na presente investigação era constituido basicamente por profissionais com predominância do sexo feminino, casados, na faixa etária de 30 a 49 anos; na sua maioria admitidos na Previdência Social a partir da década de 70. Havia prevalência de servidores em regime trabalhista e, em geral, satisfeitos no trabalho.

Considerando a existência de 23 Unidades da Federação (UF) e um Distrito Fecieral (DF), o que não apenas dificultaria a apresentação de dados em tabelas, como não haveria diferenças tão significativas de uma Unidade da Federação para outra, foi adotada a divisão político-administrativa e regional da Fundação Instituto Brasileiro de Geografia e Estatística (IBGE) utilizada por último censo, em 1980. Assim, o Brasil foi dividido em cinco Grandes Regiōes, a saber: Norte (N), Nordeste (NE), Sudeste (SE), Sul (S) e Centro-Oeste (CO).

\subsection{Nivel de preparo de enfermeiros}

$\mathrm{O}$ estudo anterior demonstrou que $71,5 \%$ dos enfermeiros pesquisados de São Paulo e Rio de Janeiro eram portadores de um título de habilitação em cursos com carga horária superior a 500 horas, ou um semestre letivo.. Esses cursos, inclusive o de Licenciatura em Enfermagem, de acordo com o currículo mínimo só podem ser realizados após a conclusão do ciclo denominado tronco profissional comum, que já permite exercer a profissão.

A presente investigação revela grande semelhança de resultados com a anterior, pois $71,3 \%$ dos enfermeiros de unidades ambulatoriais do INAMPS no Brasil, também haviam concluido cursos de especialização ou habilitação. 
Os cursos de Planejamento de Saúde e o de Enfermagem do Trabalho, mesmo com carga horária inferior a 500 horas, foram incluidos no estudo como cursos de especialização. Já os cursos de Administração aplicada à Enfermagem e de Pedagogia e Didática aplicadas à Enfermagem, enquanto oferecidos pela Escola de Enfermagem da Universidade de São Paulo, entre 1959 e 1970, eram considerados cursos de pósgraduação (legislação antiga) e, na realidade, tinham muito mais de 500 horas. Outras instituições passaram a oferecer curso de Administração de Serviço de Enfermagem, a nível de especialização (pós graduação sensu-lato), já dentro da nova legislação, com 360 horas de aulas, no mínimo. No questionário não foi solicitado ao enfermeiro discriminar tais pormenores. Assim, todos esses cursos foram considerados como formais de especialização, por atingirem um semestre letivo.

Conforme foi constatado na pesquisa anterior, e está claro também nesta, os cursos mais freqüentados foram o de Saúde Pública e o de Administração Hospitalar.

Surpreendentemente, foram encontrados no Nordeste, lotados em PAM, quatro enfermeiros que informaram ter título de mestre e um enfermeiro do Sul informou ter título de Doutor, sem mencionar a área de estudo, se em Enfermagem ou em outra.

Apesar da região Sudeste ser a mais bem aquinhoada em termos de recursos para aperfeiçoamento e pós graduação por universidades e centros de cultura e pesquisa, parece que os profissionais dessas regióes não são os maiores beneficiados.

E importante observar que do total de 927 enfermeiros de PAM, $281(30,3 \%)$ são formados em Saúde Pública e $190(20,4 \%)$ em Administração Hospitalar. Com exceção da região Sudeste, em todas as demais Grandes Regiōes, o segundo curso mais freqüentado foi o de Licenciatura em Enfermagem.

Outro dado interessante: no Nordeste, a proporção enfermeiro: curso é maior do que no Sudeste; lá, os dados indicam 1 : 1,27, correspondendo a 258 profissionais para 328 cursos; no Sudeste a proporção é de $1: 1,15$, equivalente a 474 enfermeiros para 547 cursos.

A mesma proporção, se calculada somente com o total de respostas dos enfermeiros que fizeram curso e excluindo-se os que não fizeram, passa a ser maior na região Sul, isto é, $1: 1,67$, que corresponde a 58 enfermeiros para 97 cursos.

Foi constatado pelas respostas que existem 165 enfermeiros licenciados para o magistério de $1^{\circ}$ e $2^{\circ}$ graus. Considerando que a educação para a saúde é importante para o PAM, esse número expressa um contigente com formação didática que deveria ser aproveitado para ensinar saúde aos usuários de PAM, ou para realizar treinamento do pessoal.

Pelos dados colhidos pode-se teoricamente afirmar também que, de cada três enfermeiros que atuam no PAM, um é formado em Saúde Pública; isso já constitui por si só um dado importante em termos de nivel de preparo dos enfermeiros. Se fosse possivel chamar para os PAMs os demais enfermeiros com formação em Saúde Pública traba- 
lhando em hospitais próprios do INAMPS, certamente essa proporção poderia ser aumentada. E, se cada enfermeiro com tal preparo adicional pudesse desempenhar plenamente as funções e atividades previstas nessas áreas de conhecimento, com toda certeza a instituição poderia aumentar o ritmo dos serviços produzidos e melhorar a qualidade da assistência de enfermagem a seus usuários.

Além da habilitação, a nível de graduação, e os cursos de especialização, a nivel de pós-graduação, existem ainda atividades ou programas de educação continuada, que são caracterizadas, segundo RUFINO et alii ${ }^{15}$ como "mecanismos de educação não-formal, dentro de uma psicopedagogia própria, aberta às influências do contexto sócio-político do momento histórico em que se situa".

Nesse caso, embora cada indivíduo seja responsável pelo seu próprio crescimento profissional através da participação em atividades de educação continuada, BARROSO \& VARELLA 4 atribuem tal responsabilidade também ao "sistema formador de recursos humanos e ao sistema empregador".

Quanto a essas importantes atividades de educação continuada, os dados das duas pesquisas, desta e da anterior, mostram que houve grande interesse por parte dos enfermeiros. Aliás, houve mesmo uma semelhança de resultado nos dois trabalhos; no primeiro, abrangendo apenas São Paulo e Rio de Janeiro, $82,9 \%$ dos enfermeiros informaram haver participado de uma ou mais atividades; no segundo, abrangendo todo o Brasil, o resultado foi de $84,1 \%$.

O Congresso Brasileiro de Enfermagem, um dos maiores eventos realizado anualmente pela Associação Brasileira de Enfermagem, não encontra muitos adeptos entre enfermeiros de PAM. São do Nordeste, mais uma vez, os profissionais que mais participaram desse evento, pois quase um em cada quatro dessa região respondeu ter participado, nos doze meses anteriores ao preenchimento do questionário.

3.3. Satisfação no trabalho e apoio da Chefia

O sentir-se apoiado ou prestigiado pela Chefia, seja de forma explícita ou implícita, geralmente confere segurança e estímulo a quem trabalha. E, pois, um fator que pode aumentar a produção e o rendimento das tarefas, inclusive conferindo satisfação, e até mesmo orgulho, ao trabalhadior. A própria dedicação e responsabilidade no trabalho podem ser desenvolvidas e estimuladas nos trabalhadores pela sensibilidade e habilidade de um chefe interessado em aproveitar o potencial de seus servidores, especialmente na administração de serviço público, onde não há flexibilidade salarial e rem outras formas de incentivo material.

Estudos e pesquisas americanos vêm demonstrando desde a década de 70 a estreita relação entre satisfação-insatisfação no trabalho e produtividade.

Enfermeiros de PAM foram consultados para opinarem sobre esses aspectos que, apesar de subjetivos, podem influir muito no desempenho do trabalho. 
Sondada a opinião de enfermeiros, observou-se que $75,2 \%$, ou seja, $3 / 4$ dos respondentes, consideraram que teriam apoio da chefia se quisessem implantar uma nova rotina de enfermagem. E a maioria de 766 enferrueiros $(83,6 \%)$ respondeu estar satisfeita no trabalho que realizava.

\subsection{Atividades rotineiras de unidades ambulatoriais}

Uma das questões do instrumento de pesquisa relacionava as atividades técnicas próprias de muitos PAMs, inclusive tarefas educativas e administrativas da área de Enfermagem de Saúde Pública e outras que poderiam ser identificadas como sendo de serviços básicos de saúde. Cada uma dessas atividades relacionadas estava cruzada com colunas onde foram especificadas as categorias funcionais de: enfermeiro, auxiliar de enfermagem, auxiliar operacional de serviços diversos, médico e outros, além de uma coluna intitulada "não realiza". Esta deveria ser assinalada na hipótese em que no PAM do respondente as respectivas tarefas não fossem executadas. A questão deixava também espaço aberto para outras respostas livres sobre atividades, a critério do respondente.

Nesta listagem estavam incluidas também ações não executadas na maioria dos PAMs de grandes centros urbanos, ou por falta de sistematização ou de previsão de recursos, tais como :visita domiciliária, controle de saúde de gestantes, crianças e portadores de patologias crônicas compensadas.

Cabe lembrar que tais atividades assim como outras de Enfermagem de Saúde Pública, mesmo não sendo executadas nos PAMs de grandes centros urbanos, já eram previstas em Portaria do antigo DASP 7, sobre atribuições do enfermeiro. Contudo o modelo da Previdência Social destacava, segundo o Conselho Federal de Enfermagem" a "assistência médica como a própria essência da assistência à saúde" e não possibilitava ao enfermeiro cumprir aquelas atribuiçōes previstas pelo DASP. Tal fato concorria, de acordo com aquelas entidades de classe, para "minimizar como subsidiárias as ações de outros profissionais do setor". Em consequiência disso, os enfermeiros que atuavam nos serviços previdenciários não encontravam condições e nem recursos para realizar atividades de saúde pública.

Com a implantação do SUDS (Sistema Unificado e Descentralizado de Saúde) espera-se que, após análise das dificuldades identificadas no funcionamento da rede nacional de serviços de saúde, sejam os mesmos utilizados em suas plenas capacidades operacionais, propiciando aos enfermeiros condições para desenvolvimento de suas potencialidades visando atender as necessidades da população.

3.5. Relações entre características de enfermeiros e atividades de enfermagem

Considerando que inúmeros estudos, inclusive a pesquisa realizada pelo Conselho Federal de Enfermagem ${ }^{9}$, em 1982/1983, vêm provando que existe uma relação ertre satisfação-insatisfação no trabalho e pro- 
dutividade, nesta investigação foram feitos diversos cruzamentos das respostas colhidas tendo em vista constatar tal relação.

Através desses cruzamentos seria possível verificar se havia relação entre satisfação no trabalho e as caracteristicas pessoais ou profissionais do enfermeiro, ou ainda se o nivel de preparo, o exercício de função de chefia ou a execução de determinadas atividades produziam também aquela satisfação no trabalho.

Igualmente, partindo-se do pressuposto de que o apoio explícito ou implicito por parte da chefia pode gerar satisfação no trabalho, tais caracteristicas também foram cruzadas com as atividades de enfermagem, procurando identificar a existência de possiveis relações.

\section{CONCLUSOES}

Os dados expostos e analisados no presente estudo permitem estabelecer as seguintes conclusões:

1) quanto às caracteristicas pessoais e profissionais do enfermeiro:

a) predominância do sexo feminino $(94,3 \%)$;

b) maioria constituida de casados; é interessante observar que, entre os enfermeiros de Postos de Assistência Médica (PAM), a proporção de casados é maior do que no conjunto da população brasileira, segundo dados do ANUÁRIO ESTATISTICO DO BRASIL - $1985^{1}$; isso desfaz a idéia de que o exercício da enfermagem conduz o profissional mais facilmente ao celibato;

c) quanto à idade, sobre a faixa etária de 30 a 49 anos;

d) especificamente quanto às características profissionais:

- maioria constituida de diplomados em Enfermagem e admitidos na Previdência Social, em regime trabalhista, na década de 70;

- natural predominância de profissionais sem chefia;

- maioria absoluta de enfermeiros satisfeitos com o exercício da profissão nas unidades ambulatoriais, onde contam com apoio da chefia;

e) ainda quanto às características profissionais:

- excelente nível de preparo técnico dos enfermeiros de PAM, pois $71,3 \%$ deles eram habilitados ou especializados em, pelo menos, um curso de longa duração, numa proporção de 1,62 curso por enfermeiro;

- extraordinário nivel de atualização em programas de educação continuada: constatou-se que $84,1 \%$ de profissionais haviam participado desses programas nos doze meses anteriores ao 
preenchimento do questionário, numa proporção média de 2,7 atividades por enfermeiro;

2) quanto às atividades mais executadas:

a) somente por enfermeiros: supervisão do pessoal de enfermagem, assistência direta ao cliente/paciente, ações educativas, ações administrativo-burocráticas e função de treinamento; a atividade de supervisão do pessoal de enfermagem foi a mais assinalada pelos enfermeiros, independentemente de faixa etária, de região, de cursos formais de especialização ou habilitação frequientados, de programas de educação continuada de que tivesse participado, de apoio da chefia ou de condições de satisfação no trabalho;

b) por todas as categorias profissionais: verificação de sinais vitais, preparo de ambiente e de paciente para exame médico, encaminhamentos, preparo de material para esterilização, coleta de dados estatísticos, curativos, verificação de dados antropométricos e retirada de "pontos" cirúrgicos; quase todas essas atividades são, na verdade, preparatórias para consulta médica ou decorrentes dela, pois, no INAMPS, a consulta médica continua a ser o termo para medir a grandeza e o funcionamento dos Postos e o serviço de enfermagem está diretamente relacionado com o desempenho dessas atividades;

3) quanto à existência de relações entre as caracteristicas pessoais e profissionais e as atividades executadas por enfermeiros:

a) fator satisfação no trabalho e outras variáveis:

- faixa etária e satisfação no trabalho - aumento gradual de satisfação no trabalho à medida que aumenta a idade do enfermeiro;

- exercício de chefia e satisfação no trabalho - inexistência de relação entre essas duas variáveis:

- conclusão de curso formal de habilitação ou especialização e satisfação no trabalho - ausência de relação entre essas variáveis:

- participação em programa de educação continuada e satisfação no trabalho - inexistência de relação entre essas variáveis;

- atividades de rotina diária do enfermeiro e satisfação no trabalho - maior satisfação manifestada entre enfermeiros que realizavam treinamento de pessoal e atividade educativa para clientes/pacientes do que entre os que realizavam atividade administrativa e de assistência direta;

b) fator percepção de apoio da chefia e outras variáveis:

- faixa etária e apoio da chefia - aumento gradual da percepção de apoio à medida que aumenta a idade; ; 
- exercício de chefia e apoio - maior percepção de apoio pelos que exerciam função de chefia do que pelos que não exerciam; entretanto, essa diferença não chegou a ser de $10 \%$; portanto, enfermeiros chefes que se sentiam apoiados pelas suas chefias não estavam transmitindo o mesmo grau de apoio aas seus colegas, enfermeiros se mchefia que lhes estavam subordinados;

- conclusão de curso formal de habilitação ou especialização e apoio - maior percepção de apoio da chefia entre os portadores de título de conclusão de algum curso formal, seja a habilitação ou de especialização do que entre os não portadores; entretanto, também nesse caso, a diferença percentual entre os dois dados, ter chefia ou não e sentir apoio, é muito pequena $(10 \%)$, parecendo não haver relação direta entre eles;

- participação em programas de educação continuada e apoio inexistência de relação entre essas variáveis, pois em relação ao apoio da chefia, o percentual $(\mathbf{7 3 , 1 \%})$ foi idêntico, tanto entre os que haviam participado de algum programa como entre os que não haviam participado de atividade alguma de educaçāo continuada; embora a participação nesses programas dependa de compreensão e boa vontade dos chefes que devem autorizar a dispensa de comparecimento ao serviço do servidor, os enfermeiros não perceberam nessa concessão também uma forma de apoio da chefia:

- atividades de rotina diária e apoio - maior percepção de apoio pelos enfermeiros que realizavam supervisão do pessoal de enfermagem e atividades administrativas do que pelos que estavam em funções de treinamento do pessoal e de assistência direta ao cliente/paciente.

\section{CONSIDERAÇOEES FINAIS}

Os dados levantados e estudados neste trabalho possibilitaram uma análise a respeito dos enfermeiros atuantes em unidades ambulatoriais do INAMPS no Brasil. Esse estudo permitiu caracterizar e interpretar a situação existente, bem como estabelecer relações entre os diversos aspectos que compõem tal situação. Ensejou também verificar que a maior concentração de enfermeiros encontra-se na região Sudeste, que compreende os Estados do Espirito Santo, Minas Gerais, Rio de Janeiro e São Paulo. Embora se trate de uma realidade encontrada em outras profissões, é importante salientar que, no caso da enfermagem, os dados de São Paulo e Rio de Janeiro mostraram um fenômeno curioso: dados do Conselho Federal de Enfermagem (COFEN) demonstravam que a maior população de enfermeiros cadastrados nesse órgão $(27,6 \%) \mathrm{em}$ 1984, situava-se no Estado de São Paulo, e esse mesmo Estado, neste levantamento, apresentava apenas $4,1 \%$ de enfermeiros trabalhando no INAMPS. Já o Rio de Janeiro, com uma porcentagem de $20,1 \%$ de enfermeiros cadastrados no COFEN, apresentava $27,3 \%$ de enfermeiros 
atuando no INAMPS. Em média para o Brasil, $11,8 \%$ do total de enfermeiros encontrava-se em atividade no INAMPS.

Com relação ao tipo de atividades, há muitas tarefas que o enfermeiro vem desempenhando normalmente nos Postos de Assistência Médica (PAM), e que são típicas de assistência primária ou de serviços básicos de saúde.

Assim, quaisquer que sejam os órgãos (Estado ou Prefeitura) que venham a assumir a rede de unidades ambulatoriais da Previdência Sacial, irão contar com enfermeiros lotados nessas unidades. São profissionais imprescindíveis dentro da equipe de saúde, não só pela sua formação curricular acadêmica, mas sobretudo pela qualidade do preparo técnico formal e informal de atualização, conforme demonstrado neste estudo.

E de se esperar, pois, que esses profissionais sejam requisitados e aproveitados para a expansão daqueles serviços básicos de saúde, o que muito poderá contribuir para a melhoria da assistência à saúde da população.

Por último, cabe o alerta aos enfermeiros para que coloquem a serviço dessa população todos os seus conhecimentos e habilidades profissionais e comprovar que realmente o "mundo precisa de enfermeiros" 11.

OCiUISSO, T. The profile of the nurses working the INAMPS (National Health Service) outpatent centers. Rev. Esc. Enf. USP, São Paulo, 24(1):77-92, Apr. 1990.

The objective of this study was to outline a profile of the nurses working within the INAMPS (National Health Service) outpatients centers in Brasil. Its purpose was to offer some assistance on the understanding of the subject, to the nursing educational system, to the employers of the product of that system, to the nurses' associations and to the nurses themselves.

In the pursue of the objetive, the author depicted: personal and professional traits of the nurses; job satisfaction and perceived support from the administration; the most frequent nurses activities performed. It also stablished the relations between nurses traits, jab satisfaction, perceived support, and activities performed.

Data was collected from March to December 1984. The questionnaires were sent to the universe of working nurses in the outpatient centers - 1158 nurses. 927 $(80,1 \%)$ answers were obtained. The population studied represented: $94,3 \%$ female, majority married; 30 to 40 years old, year of graduation and year of admission in the INAMPS in the 70's. Gross results were: job satisfaction 83,6\%, perception of support from administration $75,2 \%$, prepared as specialists $71,3 \%$, and frequence to continuing educational programs $84,1 \%$. Mains activities performed by nurses in decreasing order: supervision of nursing personnel 39,3\%, direct nursing care 36,7\%, teaching of patients and families $21,7 \%$, administrative - functions $17,9 \%$, and inservice training of personnel $3,6 \%$.

No relation was demonstrated between graduate preparation and job satisfaction nor perceived support from administration. Positive relation was found between educative activities and job satisfaction, and between supervision of nursing personnel or performance of administrative functions and perception of support from the administration.

UNITERMS: Nursing service. Ambulatory care. Social security Brazil. 


\section{REFERENCIAS BIBLIOGRAFICAS}

1. ANUARIO BSTATISTICO DO BRASIL: 1985. Rlo de Janeiro, Fundach̆o Instituto Bra. sileiro de Geografia e Estatistica, 1986. v. 46.

2. AQUINO, C.P. Administraç̃o de recursos humanos: uma lntrodução. São Paulo, Atlas, 1980. $270 \mathrm{p}$.

3. ASSOCLACAO BRASILEIRA DE ENFERMaGem. Perfil do enfermeiro: documento final. In:- Anaí da assombléis do dologados. Porto Alegre, 1982. p.40-4.

4. BARRoso, M.G.T. \& VARETIA, Z.M.V. Educaç̃o contintrada: requisito bissico para o crescimento profissional. In:- CONGRESSO BRASILEIRO DE ENFERMAGEM, 31., Fortaleza, 1979. Anais. Fortaleza, Associaça Brasileira de Enfermagem, 1979. p.101-6.

5. BRASIL. Leis, decretos, etc. Decreto no 94.406, de 8 de junho de 1987. Diário oficial, Brasilia, 9 de Junho de 1987. p.8853-55. Regulamenta in Lei no 7.498, de 25 de junho de 1986, que dispz̃e sobre o exercício da enfermagem e dá outras providénclas.

6. BRASIL. Leis, decretos, etc. Lel ne 7.498 , de 25 de junho de 1986 . Diário Oficial, Brasilla, 26 de junho de 1986. p.9273. Dispõe sobre a regulamentação do exercício da enfermagem e dá outras providéncias.

7. BRASIL Leis, decretos, etc. Portaria DASP no 146, de 17 de agosto de 1973. Diário Oficial, Brasilia, 31 de agosto de 1973. Suplemento. Dispõe sobre o plano de classificação de cargos - grupo outras atividades de nível superior.

8. CONSELHO FEDERAL DE ENFERMAGEM. Esboço do perfil do enfermeiro generalista. In:-__ Rolatório: 1981-82, Rio de Janeiro, 1982. f.135-9.

9. CONSELHO FEDERAL DE ENFERMAGEM. O exercício da enferm:tgem nas instituiçües de saúde do Brasil: 1982/1983 - enfermagem no contexto institucional. Rio de Janeiro, Associação Brasileira de Enfermagem, 1986. v.2.

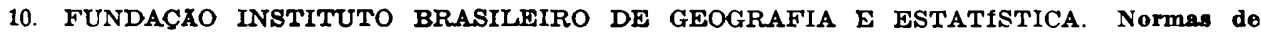
apresentacão tabular. Rlo de Janeiro, 1972 . 20p.

11. MAHLER, H. Açåo de reforma em enfermagem. Saúde no Mundo, Genebra: 2-3, dez. 1978.

12. OGUISso, T. Assisténcia primária de saúde no INAMPS $\mathrm{em}$ São Paulo $€$ no Rio de Janeiro: contribuição do enfermeiro. São Paulo, 1984. 203p. (Tese de doutorado Faculdade de Saúde Pública da USP).

13. ORGANIZAÇAO MUNDIAL DE SAƠDE. Cuidados primarios de saúde: relatório da Conferencia Internacional sobre Cuidados Primários de Saúde, Alma-Ata, URSS, 6-12 de setembro de 1978, Brasilla, UNICEF, 1979. 64p.

14. POPULACAO de enfermagem cadastrada em 30-04-84. COFEN: normam e notícias. Rio de Janeiro, $7(1 / 2):-$ Jan./Jun. 1984.

15. RUFFINO, M.C. et alli. Retrospectiva das publicaçōes de pesquisas realizadas sobre educação em enfermagem 1974-1981. Rev. Bras. Enf., Brasllia, 38(3):245-56, jul./dez. 1985.

16. SANtos, B.M.o. et alii. Proposta de um perfll do enfermeiro. Rev. Paıl. Enf., Săo Paulo, 4(4):132-4, out./dez. 1984.

Recebido em $24 / 10 / 88$ 